\title{
“Quem quer saber de professor?”: percepção docente sobre a municipalização do ensino em Porto Velho/RO
}

Eudeir Barbosa de Oliveira ${ }^{1}$

ORCID: 0000-0002-8299-5093

Marli Lúcia Tonatto Zibetti ${ }^{2}$

ORCID: 0000-0003-3939-5663

\section{Resumo}

A municipalização do ensino fundamental decorrente da divisão de responsabilidades entre União, estados e municípios foi realizada temporal e processualmente de formas muito distintas nos diferentes municípios brasileiros. 0 artigo apresenta resultados de pesquisa que analisou a última etapa do processo de municipalização, que se caracterizou pela transferência de escolas da rede estadual para o Município de Porto Velho-R0, incluindo-se os docentes que, contratados pela rede estadual, passaram a ser geridos pela rede municipal. A pesquisa teve por objetivo analisar as percepções das professoras acerca do processo de municipalização do ensino e suas implicações sobre a carreira e o trabalho docente. Participaram da pesquisa 15 professoras das seis escolas da rede estadual que foram transferidas para o Município. Os dados foram produzidos por meio de entrevistas semiestruturadas, anotações em diário de campo e análise dos documentos que regulamentam a municipalização. Os resultados indicam que, embora os discursos oficiais atribuam aos professores o papel de protagonistas nos processos educacionais, na concepção e implementação dessas mudanças, em Porto Velho/RO, não houve envolvimento docente, e os espaços de participação nas escolas não se constituíram em contextos capazes de contribuir para a formação democrática. De acordo com a Psicologia Histórico-Cultural, a ausência de espaços de apropriação da realidade histórica e política interfere na constituição da consciência crítica e altera a essência do trabalho docente, favorecendo a condição de alienação. É o que se observou no contexto analisado.

\section{Palavras-chave}

Municipalização - Trabalho docente - Participação - Subjetividade.

1- Secretaria de Estado da Educação, Porto Velho, Rondônia, Brasil. Contato: debarbosaloss@gmail.com

2- Universidade Federal de Rondônia (UNIR), Porto Velho, Rondônia, Brasil. Contato: marlizibetti@yahoo.com.br 


\section{"Who cares about the teacher?": teacher's perception of the municipalization of education in Porto Velho/RO}

\section{Abstract}

The municipalization of primary education resulting from the separation of responsibilities between the Union, States, and municipalities was carried out temporally and procedurally in distinct ways in different Brazilian municipalities. We present results of the analysis of the last stage of the municipalization process in Porto Velho/RO, in which schools from the State school system were transferred to the Municipality of Porto Velho/RO, including teachers who, hired by the State school system, were transferred to Municipality's administration. Our goal is to analyze the teachers' perceptions about the process of municipalization of teaching activities and its implications on their career and teaching work. Fifteen teachers from six state schools that were transferred to the municipality's administration participated in the research. The data were produced through semi-structured interviews, notes in a field diary, and analysis of the documents that regulate municipalization. The results indicate that, although the official speeches attribute to teachers the role of protagonists in the educational processes, in the conception and implementation of these changes, in Porto Velho/RO, there was no involvement of the teachers, and the spaces for participation in schools were not constituted in contexts capable of contributing to democratic formation. According to Historical-Cultural Psychology, the absence of spaces for the appropriation of historical and political reality interferes with the constitution of critical awareness and alters the essence of the teacher's work, favoring the alienation condition.

\section{Keywords}

Municipalization - Teacher's work - Participation - Subjectivity.

\section{Introdução}

As transformações sociais e políticas que permitiram a promulgação da Constituição brasileira de 1988 (BRASIL, 1988) desencadearam grandes mudanças no sistema educacional. Os princípios democráticos que sustentaram a abertura política e que se constituíram em bandeira dos profissionais da educação defendiam a gestão participativa das instituições escolares com investimentos públicos que garantissem educação de qualidade, socialmente referenciada, a toda a população brasileira.

Entretanto, sob um modelo econômico neoliberal, no qual os investimentos em políticas sociais são considerados gastos públicos, a descentralização de responsabilidades não foi implementada como possibilidade de ampliação da participação política dos distintos segmentos que constituem as escolas, mas como oportunidade de economia financeira, visto que a descentralização dos recursos para os municípios e para as escolas 
permitiu o atendimento de um contingente maior de estudantes com gastos menores. Sob o ideário econômico neoliberal, a gestão participativa foi instituída como distribuição de responsabilidades entre os entes federados, e a autonomia das escolas resumiu-se à adesão e execução de programas propostos e financiados no âmbito federal, de maneira a se "fazer mais com menos", por meio do estímulo à participação da comunidade para suprir a ausência do Estado (ZIBETTI; PACÍFICO; TAMBORIL, 2020).

Paro (2017) defende que participar é um ato que não está propriamente na execução das políticas, mas nas tomadas de decisão. Entretanto, esse sentido de participação não foi alcançado pelo conjunto da comunidade escolar. Na fragilidade da democracia brasileira, parece conveniente que o conceito de participação se limite ao direito ao voto, pois não há como servir aos interesses da maioria quando predominam os interesses do capital. A democracia que se consolida, portanto, determina o controle do Estado sobre as ações dos sujeitos, implicando falsa ou insuficiente autonomia.

Esta pesquisa tomou como objeto de investigação a última etapa do processo de municipalização da educação, em Porto Velho/Rondônia, considerando o contexto de implementação das mudanças decorrentes da distribuição de responsabilidades sobre a gestão dos sistemas educacionais após a Constituição de 1988, por meio da aprovação do Fundo de Manutenção e Desenvolvimento do Ensino Fundamental e de Valorização do Magistério - Fundef (BRASIL, 1996a) e da nova Lei de Diretrizes e Bases da Educação Nacional - LDBEN (BRASIL, 1996b).

0 sistema estadual de ensino em Rondônia foi instituído após a criação do Estado, em 1981, uma vez que, na condição de Território, a gestão pública era da União. A divisão de responsabilidades no âmbito educacional, prevista na Constituição federal, foi implementada gradativamente e ainda está em andamento. Em função da passagem de Território a Estado esse processo foi realizado de forma peculiar em cada município, de maneira que nenhuma das etapas de escolarização deixou de ser oferecida pelo Estado. Conforme dados apresentados no Plano Estadual de Educação elaborado para o período de 2014 a 2024, a rede estadual ainda atendia, em 2013, 2\% das matrículas na educação infantil, 33\% nos anos iniciais e 66\% nos anos finais do ensino fundamental. (RONDÔNIA, 2014a).

Esses dados impulsionaram a proposta de reordenamento que foi objeto de análise nesta pesquisa. Teve início pelo Decreto Estadual 19.077 (RONDÔNIA, 2014b), o qual instituiu o Programa de Ação e Parceria Educacional Estado-Município, para atendimento à Educação Básica e foi efetivada pelo Termo de Cooperação Técnica Educacional 36/2015 (RONDÔNIA, 2015a) e do Decreto 20.070 (RONDÔNIA, 2015b), os quais regulamentam, em todo o estado, o reordenamento do ensino.

A municipalização do ensino foi estabelecida sob o regime de colaboração entre os Governos Estadual e Municipal, que considerou as determinações dos artigos 211 e 214 da Constituição federal (BRASIL, 1988) e dos artigos 188 e 192 da Constituição estadual (RONDÔNIA, 1989). Esses artigos reforçam a garantia da educação básica como prioritária e obrigatória e a aplicabilidade dos recursos disponíveis para os seus sistemas de ensino, com garantia dos direitos e vantagens para os profissionais do magistério, em regime de colaboração entre as esferas. 0 processo de municipalização atende ainda o artigo 11, inciso V, da LDBEN (BRASIL, 1996b, n.p.), que atribui aos municípios a incumbência 
de "oferecer a educação infantil em creches e pré-escolas, e, com prioridade, o ensino fundamental”.

Em Porto Velho, o acordo entre Estado e Município está amparado pelo Decreto 21.405 (RONDÔNIA, 2016). 0 artigo 18, parágrafo $4^{\circ}$, do mesmo Decreto, autoriza a celebração de convênios entre as esferas administrativas. Além dos prédios escolares, dos equipamentos e mobiliário, a transferência integral das escolas inclui também os recursos humanos. Nessas determinações, os servidores estaduais passaram a trabalhar sob a administração municipal com ônus para o estado, sem perdas de direitos, vencimentos e vantagens. É sobre esse recorte da municipalização que a pesquisa se debruça, mais especificamente sobre a percepção das professoras envolvidas no processo.

Em levantamento feito no banco de teses e dissertações da Coordenação de Aperfeiçoamento de Pessoal de Nível Superior (CAPES), foram localizadas nove pesquisas, no período de 2009 a 2019, realizadas em programas de pós-graduação em educação em diferentes regiões do Brasil que buscaram analisar a participação docente na implementação do processo de municipalização do ensino. Entre essas pesquisas, duas consideraram que não houve participação docente durante a sua implementação, ora por falta de conhecimento dos docentes em relação aos seus direitos, ou porque realmente não foram inseridos nas discussões e elaboração dos acordos/convênios entre secretarias. (BUZAIM, 2009; NUNES, 2010). Seis pesquisas mostram que houve a participação parcial, ou seja, uma participação que ocorreu por meio da representação docente em conselhos ou sindicatos (CARAVINA, 2009; BARROS, 2009; GUTIERRES, 2010; ALVES, 2011; SARMENT0, 2012; RAMOS, 2013). E somente a pesquisa de Jampani (2012) considera que houve participação direta dos professores nas decisões.

As pesquisas evidenciaram que, embora a retórica democrática considere fundamental a participação dos professores, na prática, ainda há muitos empecilhos para efetivação desta participação, conforme evidenciam os dados apresentados neste texto. De acordo com Tomanik (2009), a psicologia enquanto ciência estuda o indivíduo na sua complexidade e nas contradições das constituições históricas. Considerando o trabalho docente como resultado do movimento histórico das políticas educacionais, esta pesquisa tomou como referencial teórico as contribuições da Psicologia Histórico-Cultural.

A análise considera o movimento histórico, social e cultural em que se constituíram os sujeitos da pesquisa. Procuramos perceber os sentimentos provocados pelas ações que determinam as subjetividades do sujeito docente, tomando como subjetividade a soma das conquistas pessoais, as histórias de vida e experiências, os sentimentos, as ideologias e as expectativas que determinam os sujeitos como seres constituídos pelas e nas relações, aqui representadas pelo contexto do trabalho docente.

\section{Trabalho docente e alienação}

As políticas educacionais que normatizaram a carreira docente alteraram as diretrizes pedagógicas sobre a atuação e a profissionalização da educação, determinando estabilidade e direitos até então não garantidos. Essas mudanças ocorreram, principalmente, após a implantação do Fundef (BRASIL, 1996a), que foi substituído e teve sua abrangência 
ampliada pelo Fundo de Manutenção e Desenvolvimento da Educação Básica e de Valorização dos Profissionais da Educação - Fundeb - o qual foi instituído pela Emenda Constitucional 53 (BRASIL, 2006) e regulamentado pela Lei 11.494 (BRASIL, 2007).

De acordo com Martins (2010), as reformas políticas descentralizadoras implementadas nos anos de 1990 conferiram um novo perfil ao trabalhador docente, visto que, além da organização da carreira e valorização da profissão, alteraram também sua identidade.

Para Oliveira (2010, p. 19):

[...] a profissionalização do magistério pode ser compreendida como um processo de construção histórica que varia com o contexto socioeconômico a que está submetido, mas que, sobretudo, vem definindo tipos de formação e especialização de carreira e remuneração para um determinado grupo social que vem crescendo e consolidando-se.

Em outro trabalho (OLIVEIRA, 2013), a autora afirma que a intensificação do trabalho docente em extensa jornada de trabalho, acrescida das atividades a ela relacionadas e das atividades de controle, alteraram o conceito de trabalho docente. De uma atividade consciente e autônoma à qual se podia atribuir o conceito ontológico de trabalho, a função docente, ao perder o sentido e o significado da atividade, passa a caracterizar-se como mera ocupação. Quando deixa de ser ocupação consciente, passa a caracterizar-se como atividade alienada.

Martins (2015, p. 26) entende que, em decorrência das novas exigências do mundo do trabalho, "[...] os indivíduos não são os sujeitos de suas próprias realizações e unicamente executam ordens recebidas [...]”. Perde-se o sentido pessoal e o significado atribuído às atividades que o sujeito desempenha. A autora acrescenta que "[...] nessas condições, as capacidades dos homens bem como as possibilidades para seu pleno desenvolvimento se reprimem e se deformam, uma vez que comprometem a efetiva utilização de todas as suas forças criadoras” (MARTINS, 2015, p. 116). A naturalidade dessas situações provoca a despersonalização do trabalho docente e leva à alienação, à passividade, à desmotivação ou ao adoecimento.

Na educação brasileira, segundo Martins (2015), as políticas educativas distanciamse do essencial para a formação humana e se aproximam cada vez mais das pretensões do capital. Simultaneamente, ascendem as investidas com vieses conservadores, ideológicos e meritocráticos, aumentando a desvalorização do ensino e do trabalho docente.

Esse fenômeno estaria ligado ao esvaziamento intelectual, cultural e ao processo de alienação provocado pelo individualismo, decorrente das condições de vida sob o capitalismo. As alternativas para superar essa condição implicam promover espaços públicos para a construção de uma sociedade crítica, consciente, inclusiva e humanamente comprometida com o bem comum, incluindo-se o âmbito da educação (MARTINS, 2010).

Para Tomanik (2009), a superficial liberdade oferecida pelas forças capitalistas melhora, aparentemente, as condições de vida ao mesmo tempo em que massifica a atividade. Além disso, a perda do controle e da autonomia sobre o trabalho geram o desgaste que resulta no processo de alienação. Assim, a excessiva determinação de tarefas, ao mesmo tempo em que indefine a essência docente, acarreta características alienantes; o 
sujeito passa a viver do trabalho e para o trabalho, distanciando-se das razões pelas quais realiza as tarefas. Uma atividade que não contribui para a formação e transformação do sujeito torna-se um fazer técnico e alienante, de modo que não corresponde à construção de uma sociedade democrática.

A base da democracia é uma concepção de política baseada na igualdade e justiça, que leva ao fim de toda forma de dominação e exclusão (BRASIL, 1988), mas, sob o regime capitalista, não se realiza. Dessa forma, em contextos de desigualdade econômica, a democracia é ilusória. A presença de sujeitos alienados no mundo do trabalho decorre da ausência de participação em contextos realmente decisórios, tais como aqueles utilizados na implantação vertical das políticas no sistema educacional brasileiro. Portanto, quando se fala em participação, é preciso investigar as formas e espaços em que ela acontece. Do mesmo modo, é preciso explicitar o tipo de democracia que se defende nos espaços políticos educacionais e o que se entende por participação democrática dos sujeitos.

\section{Método e procedimentos de pesquisa}

Trata-se de uma pesquisa de campo que investigou, sob a perspectiva de professoras do Ensino Fundamental, as formas como as docentes vivenciaram a etapa final do processo de municipalização do ensino em Porto Velho e como as mudanças implicaram o trabalho docente.

De acordo com Martins e Lavoura (2018, p. 226):

[...] a aparência fenomênica, imediata e empírica da realidade é importante e não pode ser descartada, visto que ela é o ponto de partida do processo do conhecimento - portanto, necessariamente onde se inicia o conhecimento. Entretanto, deve-se, partindo da aparência, alcançar a essência do objeto de estudo, capturar sua lógica interna de funcionamento que corresponde à estrutura e à dinâmica essencial.

Portanto, a partir das contribuições das docentes, do estudo dos documentos que constituíram o contexto das mudanças em curso, as análises foram empreendidas no sentido de compreender as vivências subjetivas das envolvidas e como o trabalho docente foi afetado. A análise pretende ir para além da aparência, considerando o objeto de estudo em seu contexto histórico, ou seja, como parte das políticas educacionais produzidas no Brasil pós-Constituição de 1988.

0 campo envolveu seis escolas que atendem exclusivamente os anos iniciais do Ensino Fundamental e a Educação Infantil, incluídas no acordo de cooperação entre as esferas estadual e municipal. A permanência em campo aconteceu no período de agosto a dezembro de 2018. 0 projeto que orienta esta pesquisa foi apresentado às diretoras das escolas municipalizadas e, após aceite da participação, foi submetido e aprovado pelo Comitê de Ética da Universidade Federal de Rondônia (CAAE No 87349918.3.0000.5300).

Participaram da pesquisa 15 mulheres professoras da Rede Estadual de Ensino, que vivenciaram as mudanças por meio da cedência das escolas onde atuavam para a Rede Municipal. Os nomes das professoras foram suprimidos e todas foram identificadas 
como Maria, diferenciadas por uma letra do alfabeto. As escolas foram identificadas com números ordinais por extenso, de Escola Primeira a Escola Sexta - ordem escolhida conforme a sequência das entrevistas realizadas.

As participantes estavam com idade entre os 41 e 65 anos, cuja maior incidência era da faixa de 40 (9 entrevistadas) e 50 anos (5 entrevistadas). Todas são graduadas e apenas duas não tinham pós-graduação lato sensu. 0 tempo de serviço das docentes variava entre 7 e 35 anos, caracterizando o grupo como bastante experiente, inclusive com algumas na iminência de se aposentar. Entre elas, 14 trabalhavam em dois turnos; algumas tinham dois contratos, um pela Secretaria de Estado da Educação e outro pela Secretaria Municipal.

Nenhuma das docentes entrevistadas fez referência à militância ou à participação no sindicato da categoria, embora o Sindicato dos Trabalhadores em Educação do Estado de Rondônia (SINTER0) agregue tanto os professores da rede estadual quanto dos municípios.

Os dados foram produzidos por meio de entrevistas semiestruturadas, gravadas e transcritas, e complementadas pelas anotações do diário de campo. Foram analisados ainda os documentos que regulamentam a municipalização do ensino. Eles serviram como dados complementares para a compreensão dos aspectos legais que envolvem o trabalho docente no contexto da pesquisa.

Netto (2011) defende que os dados por si mesmos não dizem nada, apenas mostram as expressões do objeto investigado - são a descrição do fenômeno. Para perceber o fenômeno, sob a perspectiva do materialismo histórico-dialético, não basta descrever os fatos, é preciso perceber a subjetivação para além do aparente. 0 alcance dessa realidade na sua concretude requer movimentar o pensamento abstrato, forjado pelas relações sociais e culturais que estão em constante movimento e, por isso, são contraditórias.

A análise foi desenvolvida no sentido de apreender a percepção das participantes, com base em suas subjetividades, que envolvem a soma das conquistas pessoais apropriadas a partir dos conteúdos de natureza histórica, social e cultural. As conquistas contribuem para o desenvolvimento do sujeito como um ser constituído pelas e nas relações, aqui representadas pelo contexto do trabalho docente.

\section{Resultados e discussões}

Os resultados e discussões estão organizados em três categorias, nomeadas por trechos retirados das falas das professoras: a) Vendidas de "porteira fechada": o processo sob a perspectiva das docentes; b) "Quem quer saber de professor?" Sentimentos e impactos demonstrados pelas docentes; e c) "Não temos para onde fugir": reações aos impactos provocados pelo processo de municipalização.

a) Vendidas de "porteira fechada": o processo sob a perspectiva das docentes

As contribuições das participantes permitem afirmar que elas não se perceberam como sujeitos nos processos de mudança em curso nas instituições escolares onde atuam. 
Ao contrário, sentiram-se objeto das ações governamentais, tais como os prédios ou os mobiliários inseridos nos mesmos processos de transferência.

Entre as ações a serem adotadas para a implementação da municipalização, definidas pelo Decreto 20.070 (RONDÔNIA, 2015b, n.p.), que instituiu o programa de parceria para a transferência das escolas de Ensino Fundamental em Porto Velho, estão previstas “[...] reuniões com as Escolas a serem reordenadas, Conselhos escolares, conselho tutelar, pais de alunos e demais atores envolvidos no processo". Contudo, as entrevistadas indicaram que não houve comunicação nem consulta antecipada às professoras sobre o processo de municipalização das escolas. Além disso, não há nenhum relato de que a escola tenha sido envolvida no processo, nem por meio do Conselho Escolar ou mesmo do Sindicato dos Trabalhadores em Educação.

As professoras foram unânimes em afirmar que estavam de férias e, quando retornaram, receberam a informação diretamente das diretoras de suas escolas.

[...] foi bem de cima pra baixo. Quando ficamos sabendo o processo já estava em andamento... não fomos consultados... a escola foi a última a saber... a gente se sentia assim, igual como se vende uma fazenda de porteira fechada... tudo que estava dentro da escola não podia sair. Faltava informações, faltava um documento pra gente ler. Então, nos sentíamos meio perdidas no início, muito perdidas. (Maria C, Escola Segunda, grifos nossos).

0 Termo de Cooperação prevê a gestão compartilhada entre as esferas. No entanto, a carência de informação inicial provocou diversos desencontros, pois as professoras não compreendiam quais as regras em vigor nas escolas, se as do município ou as do estado. Maria A descreve que no início foi bem complicada a adaptação:

[...] nós ficamos como o filho com duas mães. Eram regras e obrigações que vinham do Estado e outras que vinham do Município: calendário, legislação, além de duas gestoras (uma do Estado e outra do Município) e nós ficávamos sem saber a que mãe obedecer. (Maria A, Escola Primeira).

Os princípios democráticos de gestão da educação pública estabelecem o direito de escolha aos profissionais e a possibilidade de opinar e/ou discordar das decisões que os afetam. Perguntadas se elas se sentiram incluídas, no processo de municipalização da escola, Maria M responde: "Não! De jeito nenhum! As decisões estão vindo de cima para baixo. Muito de cima para baixo! Não temos participação nem escolhas. Aceitamos o que é decidido". A professora acredita que a municipalização ocorreu sem planejamento, sem participação da comunidade e sem previsão de riscos.

A participação democrática consiste em garantir voz e visibilidade aos sujeitos escolares, o que acontece por meio de planejamento participativo e da valorização da opinião docente nas mudanças políticas que afetam o interior da escola. É preciso ouvir as angústias, valorizar os anseios e desejos, reorientar os profissionais para as novas políticas - incluindo as que dizem respeito ao trabalho docente. Esses procedimentos poderiam contribuir para que as profissionais, conhecedoras da realidade educacional, contribuíssem para as mudanças e se sentissem partícipes desse processo, atribuindo sentido ao trabalho docente. (MARTINS, 2015). 
Maria E acredita que se a municipalização é para aproximar secretaria e escola, ocorreu o processo inverso - o Município é mais ausente que o Estado. Ainda que no Estado a educação já fosse carente, no Munícipio as condições de manutenção das escolas pioraram. Para a garantia de material didático, as professoras "[...] ou gastam do próprio bolso, ou a diretora providencia, muitas vezes com recurso próprio também” (Maria E).

Embora a carga horária e a organização do trabalho não tenham sido alteradas, no início foi difícil a adaptação à gestão pelo fato de a escola contar com duas diretoras e duas vices. A administração das escolas foi compartilhada durante o ano de 2016. A partir do ano letivo de 2017, a gestão financeira e pedagógica e a infraestrutura das escolas passaram para a administração do Município; no entanto, os recursos humanos (professores e funcionários de secretaria e serviços gerais) continuaram sob a responsabilidade do Estado.

As entrevistas com as participantes mostraram que nem todas têm conhecimento de que o processo de transferência das escolas entre as redes é parte da política de municipalização do ensino, que vem sendo implementada no país desde a divisão de responsabilidades entre os entes federados estabelecida pela Constituição de 1988. Algumas delas entendem essas mudanças como uma prática complexa e confusa, que atende interesses partidários e eleitorais. Nesse sentido, Maria D afirma: “[...] penso que tudo não passa de política. Se fosse para mudar alguma coisa, focavam nos problemas [...]. A dificuldade maior que eu vejo é a falta de informação e a falta de colaboração. Só chegam e jogam para a gente as coisas". Corroborando dados de outras pesquisas (BUZAIM, 2009; NUNES, 2010), a municipalização por etapas, sem ampla discussão com a sociedade, também contribuiu para que muitos profissionais ignorassem que as mudanças em curso eram decorrentes da política de municipalização.

Maria J lamenta as mudanças relativas à gestão da Escola Terceira, pois a diretora havia sido escolhida pelo voto, seguindo as determinações da gestão democrática vigente na rede estadual, mas foi substituída por uma diretora indicada pela rede municipal: “[...] ainda não entendi porque derrubam uma coisa que a gente conquistou; [...] eu trabalhei pela gestão democrática... aí trazem alguém de fora que não conhece a situação da escola”. Ela acrescenta que, no seu entendimento, "[...] as mudanças podem ser positivas, mas nesse caso traiu a democracia”.

Para Freire (2001, p. 79), “[...] a democracia demanda estruturas democratizantes e não estruturas inibidoras da presença participativa da sociedade civil no comando da representação pública”. Embora, após a abertura política dos anos 1980, a legislação brasileira tenha impresso um caráter participativo e democrático à gestão pública, a vivência democrática é um processo longo que precisa ser construído historicamente para ser apropriado pelos sujeitos como valor a ser defendido. Para que a participação seja efetiva, as instâncias democráticas no contexto educacional, tais como os conselhos de escolas, precisam ser verdadeiramente deliberativas, não apenas consultivas, conforme destaca a pesquisa de Jampani (2012).

As discussões pós Constituição de 1988 recomendavam que, ao aderir ao programa de municipalização do Ensino, o município elegesse pelo voto popular um conselho ou comissão municipal de educação. Segundo Gadotti (1989), seria dever desse órgão orientar os atores envolvidos diretamente no processo quanto às mudanças e aos prováveis impactos que pudessem ocorrer durante a sua implementação. Porém, de acordo com 
Saviani (2014), a educação brasileira é historicamente atravessada por interesses políticos e, ainda que a garantia da participação democrática esteja nos documentos oficiais, sua vivência não faz parte do cotidiano escolar, pois ainda não foi efetivada no interior da sociedade. Conforme esclarece Martins (2015, p. 42):

[...] a socialidade do homem guarda também sua historicidade, e, nesse sentido, a sociedade não é apenas o meio ao qual o homem se submete para se adaptar por força das circunstâncias, mas, sim, aquele que tem criado o próprio humano. Desta relação homem-sociedade, sustentada pelos processos de apropriação e objetivação, apreende-se que este não é objeto passivo das influências e determinações sociais, mas, acima de tudo, o sujeito de sua criação, sendo ao mesmo tempo o produto da sociedade que a produz.

Assim, a compreensão explicitada pelas participantes da pesquisa acerca do processo de municipalização decorre das vivências em que estiveram imersas. Ao que parece, as condições objetivas contribuíram para a ausência de compreensão mais ampla das transformações em curso e da mobilização dessas profissionais em direção à organização e à participação coletiva no processo, evidenciando a alienação produzida nesse contexto. Entretanto, como profissionais do ensino, também poderiam produzir questionamentos acerca desse processo, se a formação recebida e o contexto em que atuam tivessem contribuído para isso.

b) "Quem quer saber de professor"? Sentimentos e impactos demonstrados pelas docentes

De acordo com Martins (2015), o trabalho docente incide diretamente sobre a personalidade dos professores. A práxis humana, aqui representada pelo trabalho docente, é constituída pelas transformações sociais e culturais, permeadas por sentimentos e emoções vivenciadas nas relações cotidianas.

Entre os vários sentimentos percebidos nas falas das participantes, destaca-se o medo provocado pela falta de informação e a baixa expectativa quanto ao futuro da carreira. As docentes parecem não compreender amplamente as instâncias nas quais as políticas são decididas. Esse desconhecimento sugere o alheamento vivido no contexto escolar, no qual são executoras de decisões pensadas em outras instâncias.

Maria B relata que o mais preocupante é a falta de importância dada para a opinião das professoras:

[...] Não fomos informados nem consultados... em outros municípios os professores nem aceitaram que ocorresse a municipalização, aqui nem fomos informados. Nem mesmo o sindicato tem respostas nem informações quanto à municipalização... estamos trabalhando meio perdidos.

Maria C comunga a mesma percepção:

Me sinto perdida... penso que no futuro vamos ficar igual quando começamos... para onde se vai? São muitas questões sem respostas... por isso vou deixar acontecer, se for preocupar com 
isso agora, não faço o que tenho que fazer... ninguém tem informação sobre o que vai acontecer conosco quando o acordo terminar...

Maria F acredita que "faz parte da lei" a necessidade de o município se responsabilizar pela educação dos anos iniciais, mas não consegue atribuir vantagens às mudanças: "A gente não tem assistência. Pelo menos até agora não tivemos”. A professora reproduz as mesmas angústias das outras participantes: não sabe se serão demitidas e como será seu trabalho quando encerrar o Termo de Cooperação: “[...] não temos informações nem sindicato, nem Semed $^{3}$, nem Seduc ${ }^{4}$, não vejo ninguém aqui...quem quer saber de professor?”

Maria $\mathrm{G}$ entende que a maior desvantagem da municipalização é a falta de informação e não saberem para onde irão no próximo ano. Esses fatores geram medo e insegurança quanto ao futuro. Na percepção de Maria L, o mais vantajoso na municipalização do ensino é saber a quem compete a educação fundamental. Para ela, a administração municipal deveria permitir uma maior aproximação com a comunidade, mas na prática não viu diferença, pois nenhuma das redes assumiu a escola. A maior desvantagem é exatamente não ter informação quanto ao futuro dos professores. Ela assim se expressa:

E essa indefınição é que aflige. Se o Estado não tem mais escolas de $1^{\circ}$ a $5^{\circ}$ ano... E aí? Vou fazer o quê? Então, essa dúvida que fica... mexe com a gente. Eu penso que deve haver um jeito, eles vão fazer alguma coisa por nós. Mas essa falta de informação que desmotiva. Minha preocupação é essa, vou ficar à mercê do Estado, até decidirem o que vão fazer comigo. (Maria L, Escola Quinta).

A Escola Quinta fica na região mais distante do centro da cidade e a que oferece condições mais precárias de funcionamento. Assim, além da falta de informação quanto ao futuro, Maria L sente que a escola está abandonada tanto pela gestão estadual quanto pela municipal:

A escola está largada, a gente quase não tem condições de trabalho [...] não vem ninguém aqui para saber da nossa situação. Falta segurança na escola. A maioria dos nossos alunos ficam aqui só até que os pais encontrem outra vaga em outra escola; há muita rotatividade de aluno e prejudica a continuidade do trabalho. A gente não sabe até quando a escola vai aguentar. É essa situação que você está vendo, calor, falta de espaço para reforço... às vezes vamos para debaixo das árvores para aguentar.

É evidente o sentimento de abandono manifestado pelas docentes. Contudo, a falta de informações acerca do futuro da carreira parece ser a questão que mais as aflige. As professoras se guiam por informações extraoficiais que chegam à escola. Baseada nessa informalidade, Maria G relata: “[...] soube que os professores poderão ser lotados como técnicos dentro das secretarias, quando findar o Termo de Cooperação”. Diante dessa possibilidade, as professoras temem perder benefícios, ou até mesmo serem obrigadas a

3- Secretaria Municipal de Educação.

4- Secretaria Estadual de Educação. 
lecionar em algumas disciplinas ou em turmas para as quais não estão habilitadas. Esse temor denota que na mesma proporção em que há a falta de informação sobre o processo em que estão inseridas no momento, há ainda o desconhecimento acerca de seus direitos em relação ao trabalho e à carreira.

A qualidade da educação depende, entre vários fatores, da atuação docente. Para que as políticas se efetivem, no interior da escola, são necessárias ações que possibilitem aos professores condições físicas, materiais e intelectuais. Além da valorização salarial, é importante considerar as subjetividades envolvidas (ANGELUCCI, 2011). Maria F define seu sentimento como "[...] abandono... na verdade estou meio frustrada. Frustação, esse é o sentimento". As professoras se sentem sem reconhecimento, sem apoio e suas falas traduzem angústia, cansaço e desmotivação. Elas se veem numa espécie de limbo administrativo. Ao mesmo tempo em que são geridas pelas duas esferas de gestão, é nítida a sensação de não pertencer a nenhum lugar. Maria $N$ também relata que "[...] são muitas perguntas sem resposta”.

A falta de informações e a posição de passividade diante de eventos que afetam diretamente as carreiras dessas profissionais indicam a alienação constituída no processo de formação e inserção no trabalho das docentes. Segundo Paro (2017), são necessários processos formativos que permitam a leitura mais ampla do sistema político e econômico (que condiciona a constituição histórica do sistema educacional), bem como a efetivação de mecanismos que garantam a participação consciente nos processos que impactam diretamente o entorno escolar. Quanto à conscientização dos sujeitos sobre a dimensão política que envolve o trabalho docente, há a necessidade de tomar posse dos seus lugares enquanto cidadãos.

0 contexto do trabalho docente define-se pelas transformações políticas, históricas e econômicas, marcado ainda pelas relações capitalistas que alienam. Nesse sentido, é importante compreender a quem interessa a passividade das professoras e o alheamento às informações e aos seus direitos. É imprescindivel que o trabalho docente seja um espaço que permita o enfrentamento às determinações do capitalismo, que alienam o trabalhador da sua essência enquanto sujeito histórico, social e singular. Daí surge a necessidade de uma formação crítica que permita o entendimento do lugar da educação na construção de novas possibilidades de compreensão da realidade.

c) "Não temos para onde fugir": reações aos impactos provocados pelo processo de municipalização

0 trabalho docente é parte do conjunto de ações necessárias para que a escola aconteça enquanto instituição organizada. A partir de uma perspectiva mais humana, Martins (2015) entende que o trabalho docente influencia diretamente a personalidade e que a ação exercida pelo trabalho, enquanto atividade, determina a subjetividade do sujeito, que por sua vez é refletida nas ações e reações diante dos conflitos. Essas ações, objetivadas pelas falas dos sujeitos, são subsídios para o pesquisador compreender além do aparente e, por meio delas, identificar as possiveis ações e reações que o processo de municipalização provoca nos participantes. 
No contexto da pesquisa aqui apresentada, Maria J se posiciona: “[...] não me preocupo, pois o Termo [de Cooperação] termina agora, eram só três anos e também já estou perto de me aposentar". Tentamos fazer uma provocação, lembrando-lhes que, segundo o que consta no Termo de Cooperação, a doação permanente era apenas dos bens materiais, e, em algum momento, os professores seriam devolvidos para o Estado. Maria K responde: "Sim, isso é verdade. Mas eles vão ter que dar um jeito".

Maria D relata que sua maior preocupação é que “[...] não sabemos para onde vamos nem o que vai acontecer conosco. Eu vou ter que procurar uma nova escola? O Estado vai continuar conosco? Eu não sei o que vão fazer... não tem pra onde fugir". Maria H fala em tirar licenças-prêmio atrasadas e esperar em casa pela aposentadoria. Maria I também responde que está se preparando para aposentar. Maria G, entretanto, não tem idade para se aposentar e explicita que, para ela, o que resta é esperar pelas soluções que a Secretaria de Educação trará: "Eu imagino que vou ficar à disposição da SEDUC, não sei fazendo o quê [...], mas o que me resta é esperar, não dá para fazer planos”.

Maria I relata que, para deixar a escola, deveria ter um local certo para lotação, mas ela sabe que no Estado não há mais oferta das séries iniciais. Além disso, entende que "[...] o Município não tem capacidade para aderir todos esses professores na rede...”. Segundo Maria A, o Município “[...] não tem estrutura para absorver toda essa demanda que está passando para ele, nem tem servidores suficientes para atender esses alunos”.

Maria F faz uma autocrítica ao responder acerca de sua situação: "Olha, talvez eu tenha me acomodado, talvez queira continuar aqui pela localização”. Maria 0 expressa preocupação sobre o processo de municipalização:

[...] para falar a verdade não pensei muito na minha carreira. Minha preocupação é o que vai acontecer. Vão prorrogar esse acordo? Até quando vamos trabalhar para o Município? A escola vai voltar para o Estado? são várias questões sem resposta. [...] os órgãos responsáveis por essas políticas poderiam pensar um pouco mais nos professores [...] porque na verdade quem carrega a educação nas costas é o professor.

Para Maria G, a falta de informação acerca dos procedimentos adotados na municipalização do Ensino trouxe um impacto muito grande para os professores. Porém, acredita que o impacto maior ocorrerá quando vier a notícia de que o Termo finalizou e elas tiverem de deixar a escola, principalmente pelo fato de que muitos servidores da Escola Terceira são idosos, trabalham lá há muitos anos e estão apenas aguardando a aposentadoria. Iniciar em uma escola diferente, a essa altura da vida, poderá provocar muitos sentimentos negativos. Mas, para ela, pior é não ter informações: “[...] aliás, eu gostaria de saber se em algum momento eles vão falar com a gente”.

Essa contradição aparece em várias falas das professoras: ao mesmo tempo que gostariam de saber o que vai acontecer, preferem esperar. A expectativa de adiar as ações ou delegar a outros a responsabilidade de resolver os problemas aparece em muitas falas: "a gente ouve falar", "isso é o que dizem", "não tem nada oficial" - as informações do "diz-que-me-diz", como nomeou Maria G. Questionamos então se foram até a Secretaria de Educação em busca de informações mais precisas. Maria G acredita que essa ação causaria preocupação antes da hora, então é melhor esperar. Maria I demonstra a insegurança que 
sente, pois afirma que "[...] a diretora informou que está tudo certo, que a Seduc não vai mexer com ninguém”, porém reforça que são informações verbais, não há nada oficial.

Dúvidas e falta de informações deixam as professoras angustiadas, com insegurança quanto ao futuro. No entanto, as reações de passividade remetem-nos a duas perspectivas preocupantes: a primeira diz respeito ao grupo de professoras que se encontra próximo à aposentadoria, e, portanto, não demonstra preocupação em relação ao futuro profissional; o segundo grupo remete-nos a um sentimento de segurança em função da estabilidade na carreira, que faz com que as professoras acreditem que a Secretaria de Educação “dará um jeito”.

É importante analisar a essência desses comportamentos para além da aparência, pois se observou ausência de iniciativas de auto-organização para o entendimento das mudanças, que podem afetar a garantia de direitos tanto do grupo de docentes envolvidas, quanto das crianças e suas famílias, atendidas pelas escolas que estão sendo objeto de transferência para a Rede Municipal.

Os autores que embasaram a pesquisa nos ajudam a compreender que a subjetividade expressa no discurso das professoras ouvidas foi constituída pelos sentidos e significados produzidos nos contextos sociais em que se formaram e trabalham. 0 processo político que as alienou da função social da educação, objetificando-as na implementação das políticas públicas, pode ter contribuído para essa postura de alienação diante das decisões que lhes são infringidas.

\section{Considerações finais}

A municipalização do ensino é parte do processo histórico vivido pela sociedade brasileira na busca pela divisão de responsabilidades entre a União, os estados e os municípios, visando a maior participação local nas decisões políticas. 0 trabalho docente, como elemento constitutivo do sistema educacional, foi diretamente impactado por essas alterações. As análises empreendidas nesta pesquisa, portanto, consideraram a municipalização como política nacional, analisando a forma como está sendo implementada no Município de Porto Velho/R0, como etapa final desse processo no âmbito local.

Os dados indicam que, embora os discursos oficiais atribuam aos professores o papel de protagonistas nos processos educacionais, na concepção e implementação das políticas não há envolvimento docente; os espaços de participação na escola não têm se constituído em contextos de vivência capazes de contribuir para a formação democrática. Essa realidade foi explicitada pelas docentes ouvidas, ao demonstrarem que se sentem excluídas dos processos decisórios e que têm uma compreensão limitada do alcance e da origem das transformações decorrentes da municipalização.

Questionadas a respeito da forma como ocorreu o processo de transferência das escolas da Rede Estadual em que atuam para o a Rede Municipal, as docentes afirmaram unanimemente que não participaram de qualquer diálogo entre as escolas e as secretarias de educação. As profissionais foram comunicadas acerca das alterações no início do ano letivo, quando a gestão das escolas passou a ser compartilhada por diretoras das duas 
secretarias. Tratou-se de um processo que não foi exclusividade do estado de Rondônia, conforme apontam as pesquisas de Buzaim (2009) e Nunes (2010).

Os direitos da carreira e da jornada de trabalho foram mantidos, porém o processo implicou situações de instabilidade e falta de informação no que se refere à formação docente e funcionamento das escolas. Os sentimentos expressos pelas docentes em relação às mudanças e ao futuro profissional foram de insegurança e angústia, embora esses sentimentos não tenham resultado em ações das envolvidas em busca de informações ou alterações da realidade em que se encontram.

A constituição da subjetividade docente, de acordo com as contribuições da Psicologia Histórico-Cultural, remete-nos aos contextos em que a formação e a atuação docente são estabelecidas. A ausência de espaços de discussão e formação, de planejamento participativo como oportunidade de desenvolvimento da consciência crítica, em que as professoras não conseguem se apropriar da função social do seu trabalho dentro dos limites da sociedade capitalista, leva à alienação. Em tese, o trabalho docente consiste em educar, formar e transformar conhecimentos; no entanto, quando executado de forma alienada e alienante, perde o sentido e passa a representar mera atividade para a sobrevivência.

Segundo a Psicologia Histórico-Cultural, a mera execução da atividade não constitui a consciência do trabalhador, mas sim exige a compreensão do contexto em que são produzidas as relações humanas na sociedade em que estamos inseridos e a apropriação das formas de sua organização. Para isso são necessários processos formativos e espaços de atuação que desenvolvam e requeiram ferramentas e conhecimentos que garantam a leitura crítica da realidade.

Conforme aponta Martins (2015, p. 133), com base nas afırmações de Marx, na III Tese sobre Feuerbach, o próprio educador precisa ser educado. Para a autora:

[...] essa tese é um convite a que se reflita que os educadores não nascem educados, sendo eles próprios sujeitos ou objetos de um desenvolvimento histórico, biográfico, que encarna uma classe social, das condições objetivas de vida, desenvolvimento este mediado das próprias relações que estabelecem para com os conhecimentos sistematizados.

Para além da qualidade da formação inicial, é imprescindível que os espaços escolares se constituam em contextos de ampliação da compreensão das forças em jogo na produção da vida em sociedade, de maneira que o conhecimento, mesmo sob as contradições do capitalismo, possa estar a serviço da humanização. Nesse sentido, os coletivos escolares precisam ser fortalecidos para que os educadores se eduquem coletivamente na luta pela superação de políticas educacionais a serviço da alienação de quem ensina e, consequentemente, de quem aprende, implicando diretamente a qualidade do ensino, como indica a pesquisa de Jampani (2012).

Novas investigações a respeito da apropriação das políticas educacionais pelos sujeitos escolares, sejam eles alunos ou professores, podem contribuir para que possamos compreender melhor as consequências dessas mudanças na constituição das escolas que temos, especialmente quanto aos processos de municipalização do ensino. 


\section{Referências}

ALVES, Charles Alberto de Souza. A política de municipalização do ensino fundamental no estado do Pará a partir da ótica dos gestores estaduais da educação. 2011. 192 f. Dissertação (Mestrado em Educação) - Universidade Federal do Pará, Belém, 2011.

ANGELUCCI, Carla Biancha. A inclusão escolar de pessoas com necessidades especiais na rede estadual de São Paulo: a dissimulação da exclusão. In: VIÉGAS, Lygia de Souza; ANGELUCCI, Carla Biancha (org.). Políticas públicas em educação: uma análise crítica a partir da psicologia escolar. São Paulo: Casa do Psicólogo, 2011. p. 187-228.

BARROS, Antônio Carlos Martins. A política salarial dos professores da rede pública no contexto da municipalização do ensino no estado do Pará. 2009. 149 f. Dissertação (Mestrado em Educação) Instituto de Ciểncias da Educação, Universidade Federal do Pará, Belém, 2009.

BRASIL. Presidência da República. Constituição Federal. Brasília, DF: Presidência da República, 1988. Disponível em: http://www.stf.jus.br/arquivo/cms/legislacaoConstituicao/anexo/CF.pdf. Acesso em: 10 maio 2019.

BRASIL. Presidência da República. Emenda Constitucional n 53. Dá nova redação aos arts. $7^{0}, 23$, 30, 206, 208, 211 e 212 da Constituição Federal e ao art. 60 do Ato das Disposições Constitucionais Transitórias. Brasília, DF: Presidência da República, 2006. Disponível em: http://www.planalto.gov.br/ ccivil_03/constituicao/Emendas/Emc/emc53.htm Acesso em: 03 jun. 2020.

BRASIL. Presidência da República. Lei 9.394/1996. Estabelece as diretrizes e bases da educação nacional. Brasilia: Senado Federal, 1996b. Disponível em: http://www2.senado.leg.br/bdsf/item/id/-529732. Acesso em: 08 mar. 2019.

BRASIL. Presidência da República. Lei 9.424/1996. Dispõe sobre o Fundo de Manutenção e Desenvolvimento do Ensino Fundamental e de Valorização do Magistério e dá outras providências. Brasília, DF: Presidência da República, 1996a. Disponível em: http://www.planalto.gov.br/ccivil_03/LElS/L9424.htm. Acesso em: 02 jul. 2019.

BRASIL. Presidência da República. Lei 11.494/2007. Regulamenta o Fundo de Manutenção e Desenvolvimento da Educação Básica e de Valorização dos Profissionais da Educação - FUNDEB [...]. Brasília, DF: Presidência da República, 2007. Disponível em http://www.planalto.gov.br/ccivil_03/_ ato2007-2010/2007/lei/l11494.htm. Acesso em: 2 jul. 2019.

BUZAIM, Railda Soares. A municipalização e a institucionalização do sistema municipal de ensino em Goiatuba/G0 (1997-2004): avanços e retrocessos do processo de democratização da Educação Básica. 2009. 178f. Dissertação (Mestrado em Educação) - Universidade Federal de Goiás, Goiânia, 2009.

CARAVINA, Maria Solange. Impacto da municipalização do ensino fundamental público sobre as condições de trabalho dos professores no município de Presidente Prudente/SP. 2009. 185 f. Dissertação (Mestrado em Educação) - Universidade Estadual Paulista Júlio de Mesquita Filho, Presidente Prudente, 2009.

FREIRE, Paulo. Política e educação: ensaios. 5. ed. São Paulo: Cortez, 2001.

GAD0TTI, Moacir. Sistema municipal da educação. In: GADOTTI, Moacir; ROMÃ0, Eustáquio (org.). Município e educação. São Paulo: Cortez, 1989. p. 71-102. 
GUTIERRES, Dalva Valente Guimarães. A municipalização do ensino no município de Altamira/PA e suas implicações para a democracia educacional. 2010. (Tese de Doutorado) - Universidade Federal do Rio Grande do Sul, Porto Alegre, 2010.

JAMPANI, Ilzete Aparecida. A municipalização do ensino fundamental no município de Junqueirópolis/ SP: 0 olhar dos profissionais do magistério sobre o processo. 2012. Dissertação (Mestrado em Educação) - Universidade Estadual Paulista, Júlio de Mesquita Filho, Presidente Prudente, 2012.

MARTINS, Lígia Márcia. O legado do século XX para a formação de professores. In: MARTINS, Lígia Márcia; DUARTE, Newton (org.). Formação de professores: limites contemporâneos e alternativas necessárias. São Paulo: Cultura Acadêmica, 2010. p. 13-31.

MARTINS, Lígia Márcia. A formação social da personalidade do professor: um enfoque vigotskiano. Campinas: Autores Associados, 2015.

MARTINS, Lígia Márcia; LAVOURA, Tiago Nicola. Materialismo histórico-dialético: contributos para a investigação em educação. Educar em Revista, Curitiba, v. 34, n. 71, p. 233-239, set./out. 2018. Disponível em: http://www.scielo.br/pdf/er/v34n71/0104-4060-er-34-71-223.pdf. Acesso em: 08 mar. 2019.

NETTO, José Paulo. Introdução ao estudo do método de Marx. São Paulo: Expressão Popular, 2011.

NUNES, José Luís Feijó. Políticas públicas e descentralização: 0 impacto da Municipalização na prática docente. 2010. 260 f. Tese (Doutorado em Educação) - Pontifícia Universidade Católica de São Paulo, São Paulo, 2010.

OLIVEIRA. Dalila Andrade. As políticas de formação e a crise da profissionalização docente: por onde passa a valorização? Revista Educação em Questão, Natal, v. 46, n. 32, p. 51-74, 2013. Disponível em: https:// periodicos.ufrn.br/educacaoemquestao/article/view/5122. Acesso em: 08 out. 2018.

OLIVEIRA, Dalila Andrade. Os trabalhadores da educação e a construção política da profissão docente no Brasil. Educar em Revista, Curitiba, , n. esp., p. 17-35, 2010. Disponível em: http://www.scielo.br/pdf/er/ nspe_1/02.pdf. Acesso em 14 out. 2018.

PARO, Vitor Henrique. Gestão democrática da escola Pública. São Paulo: Ática, 2017.

RAMOS, Marilu Dascanio. Formação continuada de professores: novos arranjos institucionais após a descentralização do ensino. Campinas: Unicamp, 2013.

RONDÔNIA. Decreto 20.070/2015. Institui programa para universalizar o atendimento do Ensino Fundamental. Diário Oficial, Porto Velho, n² 2767, p. 11-14, 24 ago. 2015b.

RONDÔNIA. Decreto 21.405/2016. Repassa ao Município de Porto Velho as escolas da Rede Pública Estadual de Ensino que especifica e dá outras providências. Diário Oficial, Porto Velho, $n^{0} 215$, p. 3-4, 21 nov. 2016.

RONDÔNIA. Assembleia Legislativa. Constituição do Estado de Rondônia. Porto Velho: Assembleia Legislativa, 1989. Disponível em: https://www2.senado.leg.br/bdst/bitstream/handle/id/70438/CE_ Rondonia.pdf?sequence=14. Acesso em: 23 abr. 2019. 
RONDÔNIA. Governadoria. Decreto 19.077/2014. Institui o Programa de Ação de Parceria Educacional Estado-Município, para atendimento à Educação Básica. Porto Velho: Governadoria, 2014b. Disponível em: http://ditel.casacivil.ro.gov.br/COTEL/Livros/Files/DEC19077.pdf. Acesso em: 02 ago. 2019.

RONDÔNIA. Secretaria de Estado da Educação. Plano Estadual de Educação de Rondônia - 2014 a 2024. Porto Velho: Seduc/RO, 2014a. Disponível em: http://ditel.casacivil.ro.gov.br/COTEL/Livros/Files/ L3565.pdf. Acesso em: 17 out. 2017.

RONDÔNIA. Secretaria de Estado da Educação. Termo de cooperação técnica e educacional 36//2015. Dispõe sobre a implantação do Programa de Parceria Educacional Estado-Município. Porto Velho: Seduc/ R0, 2015a. Disponível em: http://www.diof.ro.gov.br/data/uploads/2016/01/Doe-_30_12_2015. pdf. Retificado pela Portaria 42/2016-GAB/SEDUC. Disponível em: https://www.jusbrasil.com.br/ diarios/107723214/doero-21-01-2016-pg-42. Acesso em: 26 out. 2017.

SARMENTO, Albertina Paes. A municipalização do ensino fundamental no município de Alumínio/SP: entre o pedagógico e o poder local. 2012. 113 f. Dissertação (Mestrado em Educação) - Universidade de Sorocaba, Sorocaba, 2012.

SAVIANI, Demerval. Sistema nacional de educação e plano nacional de educação. Campinas: Autores Associados, 2014.

TOMANIK, Eduardo A. 0 sujeito humano e o conhecimento: constituição psicossocial e complexidade. In: TOMANIK, Eduardo A.; CANIATO, Ângela Maria Pires; FACCI, Marilda Gonçalves Dias (org.). A constituição do sujeito e a historicidade. Campinas: Alínea, 2009. p. 33-104.

ZIBETTI, Marli Lúcia Tonatto; PACÍFICO, Juracy Machado; TAMBORIL, Maria Ivonete Barbosa. Políticas educacionais em Rondônia e o enfrentamento às dificuldades escolares: breve panorama do período pósconstituição de 1988. In: TADA, Iracema Neno Cecilio; SOUZA, Marilene Proença Rebello de; FACCI, Marilda Gonçalves Dias (org.). Fracasso escolar: história, políticas educacionais e possibilidades de enfrentamento. Porto Velho: Edufro, 2020. p. 189-215.

Recebido em: 19.01.2020

Revisado em: 14.04.2020

Aprovado em: 04.06.2020

Eudeir Barbosa de Oliveira é professora da educação básica do Estado de Rondônia, mestre em psicologia pela Universidade Federal de Rondônia e graduada em pedagogia pelo Centro Universitário Claritiano.

Marli Lúcia Tonatto Zibetti é professora da Universidade Federal de Rondônia, com mestrado e doutorado pelo Instituto de Psicologia da Universidade de São Paulo e pós-doutorado pela Faculdade de Educação da Universidade de São Paulo. 